This is a non-peer reviewed preprint submitted to EarthArXiv.

\title{
Airborne methane surveys pay for themselves: An economic case study of increased revenue from emissions control
}

\author{
Forrest Johnson $^{\mathrm{a}^{*}}$, Andrew Wlazlo ${ }^{\mathrm{a}}$, Ryan Keys ${ }^{\mathrm{a}}$, Viren Desai ${ }^{\mathrm{a}}$, Erin B. Wetherley ${ }^{\mathrm{b}}$, \\ Ryan Calvert ${ }^{\mathrm{b}}$, Elena S.F. Berman ${ }^{\mathrm{b}}$ \\ ${ }^{a}$ Triple Crown Resources, 1722 Routh St., Suite 1750, Dallas, TX 75201

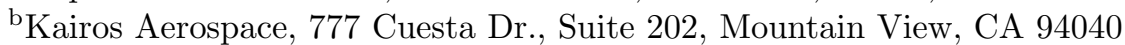

\begin{abstract}
We present an economic analysis of an emissions monitoring and capture program for a mid-sized Permian Basin operator, Triple Crown Resources ("Triple Crown"). Data from this campaign was gathered using repeat airborne surveys provided by Kairos Aerospace ("Kairos"). Key findings include:

- The total volume of detected emissions from Triple Crown operations decreased by $70 \%$ from the first to the second survey.

- Captured gas revenue in the first month was approximately $\$ 139,000$ and paid for the full cost of the first campaign (including survey, follow-up inspection, and repair) within 5 days.

- Analysis of emissions detected from a range of anonymized Permian Basin operators show that a mid-sized operator with a median emissions profile could expect a campaign to pay back in 16.8 days.

- Gas samples collected from various points across Triple Crown's operation showed significant variation in gas value, with tank vapor gas priced as high as $\$ 22 / \mathrm{MCF}$.

- Kairos survey technology was found to be an effective and highly competitive option for carbon reduction relative to wind, solar, and LED lighting, achieving a cost of $\$ 0.54$ for every one tonne of $\mathrm{CO}_{2} \mathrm{e}$ eliminated.
\end{abstract}

\section{KEYWORDS}

Emissions reduction; Methane; Payback; Airborne survey; ESG; Carbon liability

\section{Introduction}

Natural gas will play a critical role in the global energy portfolio over the coming decades (IEA, 2020; Safari et al., 2019). As such, it is likely that the market for gas will continue to grow as global energy demand increases (Alam et al., 2017). At the same time, production continues to expand in basins such as the Permian in the United States, and with this has come increasing emissions of natural gas into the atmosphere (Feijoo et al., 2018; Rutherford et al., 2020).

These gas emissions are lost revenue for oil and gas exploration and production companies. Yet the significant investment of time and money required by many traditional forms of leak detection and repair (LDAR) often cancel out or otherwise reduce the economic benefit gained by fixing large emission sources. Optical gas imaging (OGI), Method 21, or simple audio, visual, and olfactory (AVO) evaluation usually necessitate

*Corresponding author email: fjohnson@triplecrownresources.com 
This is a non-peer reviewed preprint submitted to EarthArXiv.

a site visit and inspection by an experienced crew (Johnson et al., 2020; Ravikumar et al., 2018). Moreover, these approaches are used in a find-and-fix work practice, where the order of repair is dictated by the order in which it is detected, and by extension controlled by available manpower and crew scheduling. Thus, the largest emissions that are the largest losses of revenue could continue undetected while crews focus on fixing smaller detected leaks.

However, new leak detection technology that enables effective, field-wide emission detection and quantification are not subject to the same cost and prioritization limitations of traditional LDAR. Airborne surveys quickly scan entire assets, identify precise emission source locations, and quantify emission rates (Sridharan et al., 2020). This is especially important given the evolving understanding of the distribution of emission sizes across a field, where just a small handful of sources are responsible for the majority of emissions (Brandt et al., 2016; Duren et al., 2019). The efficiencies of this approach reduce the overall cost of detecting emissions and change the equation in regard to the profitability of finding and fixing emissions.

In this paper, we explore this technology through a case study of Triple Crown. Triple Crown is a private operator in the Southern Midland Basin, specializing in drilling, producing, and capturing hydrocarbons, with a focus on Environmental, Social, and Corporate Governance (ESG). In 2020, Triple Crown contracted Kairos to conduct two field-wide airborne natural gas emissions surveys. All of Triple Crown's operated assets were included in the surveys. An economic analysis of these surveys, enhanced by results from a Permian Basin-wide survey of emissions, is presented.

\section{Methods and Data}

\subsection{Survey, inspection and repair}

Two complete airborne surveys of Triple Crown's operating assets, each covering approximately 27,000 acres and encompassing 170 surface assets and 31 miles of natural gas pipeline, were completed in early November 2020 (first survey) and in late March 2021 (second survey). For the purposes of this study, one mile of pipeline is treated as one asset.

The methane detection technology deployed in this study utilized a sensor payload, Kairos' LeakSurveyor technology (LeakSurveyor), mounted aboard a Cessna 182 and flown at an altitude of 3000 feet above ground level, collecting a swath of imagery approximately 0.5 miles wide and with a pixel resolution of approximately 10 feet. The wide swath allowed for multiple passes over operating assets. LeakSurveyor consists of an integrated imaging spectrometer, optical camera, GPS, and inertial motion unit (see Berman et al., 2020 for a detailed description of the technology). This technology has been independently verified in a peer-reviewed, single-blind third-party study to detect methane plumes with a high probability of detection and quantify the rate of the emission with high accuracy (Sherwin et al., 2021). Data is processed in-house by Kairos, passing through stages of methane retrieval, georeferencing, quality checks, automated plume detection, and final analyst verification.

Upon being notified of an emission, ground crews were quickly dispatched to validate the detection, determine the source, make any needed repairs, and then confirm with an OGI camera that the repairs were successful. Crews received a detailed report for each detection, including: the identified asset from which the emission was occurring, precise latitude and longitude coordinates of each detection, observation time and date 
This is a non-peer reviewed preprint submitted to EarthArXiv.
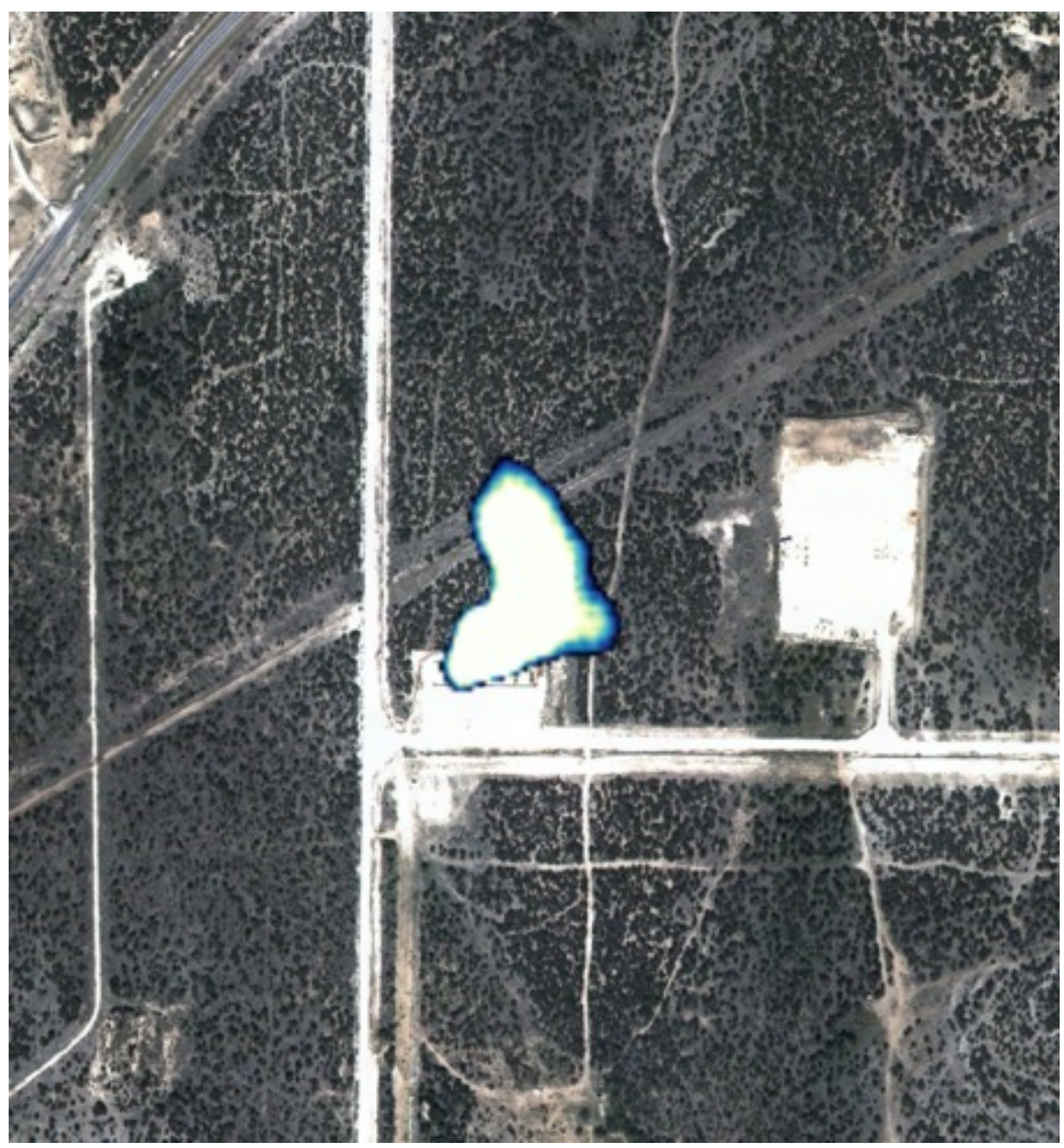

Figure 1. Image of a confirmed natural gas emission over a tank battery, overlaid upon simultaneouslycollected high resolution optical imagery. The plume is colored from blue to white, with white indicating the areas with the highest concentration of detected methane. 
This is a non-peer reviewed preprint submitted to EarthArXiv.

Table 1. Description of the data used to model Permian Co. Data drawn from case study, DrillingInfo.com, and a Permian Basin-wide survey of emissions conducted by Kairos Aerospace.

\begin{tabular}{|c|c|c|}
\hline & Value & Source \\
\hline Operators $(\#)$ & 25 & $\begin{array}{l}\text { Permian operators ( } 1000 \text { wells) for which }>25 \% \\
\text { of operating assets were surveyed by Kairos. }\end{array}$ \\
\hline Assets (\#) & 200 & Median number of well assets across 25 operators. \\
\hline Detected emission sources (\#) & 9 & Data from Triple Crown Case Study. \\
\hline $\begin{array}{l}\text { Asset-normalized emission rate } \\
\text { (MCF/Day/Surveyed Asset) }\end{array}$ & $0.87,2.50,5.91$ & $\begin{array}{l}\text { The } 25^{\text {th }}, 50^{\text {th }} \text {, and } 75^{\text {th }} \text { percentile of detected } \\
\text { asset-normalized emission rates across } 25 \text { operators. }\end{array}$ \\
\hline Total emission rate (MCF/Day) & $175,500,1182$ & $\begin{array}{l}\text { The } 25^{\text {th }}, 50^{\text {th }} \text {, and } 75^{\text {th }} \text { percentile asset-normalized } \\
\text { emission rates scaled to a } 200 \text { asset operation. }\end{array}$ \\
\hline Total cost $(\$)$ & 30,000 & $\begin{array}{l}\text { Combined cost of Kairos Survey }+ \text { ground inspection } \\
+ \text { repair. Real world costs will very by operation. }\end{array}$ \\
\hline
\end{tabular}

(which could be more than once when a single emission source was imaged multiple times), and the precise rate (MCF/Day) of the emission. Crews also received an image of each detection (see Figure 1 for an example).

The total combined cost of one survey plus follow-up ground LDAR of identified assets (collectively referred to here as a "campaign") was $\$ 23,675$. This cost was specific to this case study, and would be expected to vary based on asset density, proximity to main roads, the number of detections that require ground inspection follow up, and the nature of the required repairs.

\subsection{Post-survey analysis and modeling}

The results of the survey campaign, including costs, the quantified leak rates, and captured gas revenue, were analyzed to quantify campaign return on investment (ROI). Identical analysis was applied to a set of modeled Permian operators ("Permian 25 Co.", "Permian 50 Co.", and "Permian 75 Co.", collectively referred to as Permian Co.), which represent an operation with low, medium, and high field-scale emissions (respectively) relative to other Permian operations (Table 1).

"Typical" emission estimates for each modeled operator were based on a Permian Basin-wide survey of emissions collected by Kairos in the Fall of 2020. Screening 100,000 assets across $10,671 \mathrm{mi}^{2}$, the survey detected 914 emission sources ranging in size from 11.7 to $26,272 \mathrm{MCF} /$ Day. The present study analyzed 25 small- to mid-sized operations that had $>25 \%$ of their active assets imaged by the survey (according to DrillingInfo.com). Operators with $>1000$ assets were excluded from analysis to ensure that Permian Co. results would be comparable with the Triple Crown case study. Survey data was used to calculate an asset-normalized emission rate (MCF/Day/Surveyed Asset) for each of the 25 operators. The $25^{\text {th }}, 50^{\text {th }}$, and $75^{\text {th }}$ percentile value of assetnormalized emission rates were calculated from this range, and assigned to Permian 25 Co., Permian 50 Co., and Permian 75 Co., respectively.

Comparable survey costs were ensured by modeling Permian Co. as a 200 asset operation, matching the approximate median size of the 25 operators and similar to the number of Triple Crown assets. Ground inspection and repair costs were based on the probability of detecting an emission at a given asset in Triple Crown's first campaign. Because Triple Crown is a relatively condensed operation (contracted LDAR consulting firm can survey 12 Triple Crown tank batteries in a day, versus 4 to 8 tank batteries with other operators), the Permian Co. cost was adjusted upward, making the total campaign cost $\$ 30,000$. This also produced a more conservative estimate of economic benefit for Permian Co. 
This is a non-peer reviewed preprint submitted to EarthArXiv.

Table 2. Gas sample analysis used to build each index.

\begin{tabular}{rccc}
\hline & \multicolumn{3}{c}{ Gas Sample Composition } \\
COMPONENT (MOL\%) & DGX & WGX & VGX \\
\hline METHANE & 100 & 72.7 & 15.6 \\
ETHANE & 0 & 11.7 & 21.6 \\
PROPANE & 0 & 7.3 & 36 \\
I-BUTANE & 0 & 0.5 & 4.1 \\
N-BUTANE & 0 & 2 & 15.4 \\
NATURAL GASOLINE & 0 & 1.3 & 6.8 \\
CONTAMINANTS & 0 & 4.5 & 0.5 \\
\hline
\end{tabular}

\subsection{Captured wet gas and tank vapor value analysis}

Measuring the ROI of the campaign required quantifying the value of captured wet gas, tank vapor, and dry gas leaking from common areas of the well stream, based on gas composition (Table 2). To determine the value of these streams we utilized over 10 years of daily EOD settlement data from the CME Group to construct: [i] a wet gas price index ("WGX"), [ii] a tank vapor gas price index ("VGX"), and [iii] a dry gas price index ("DGX"). We constructed these proprietary futures indices based on the value and composition of Triple Crown's wet, tank vapor, and dry gas streams, respectively.

The dry gas/DGX futures index was built using Henry Hub natural gas and Waha basis differential. The DGX was created to represent the value of a gas stream that does not contain natural gas liquids. Using the DGX price calculates a conservative ROI on the campaign, assuming Triple Crown only captures the quantified methane as a result of the repair.

The wet gas/WGX futures index was built using a gas sample taken on the lowpressure side of Triple Crown's sales point to quantify the value of gas leaked in common areas of the well stream, such as back pressure valves, dump valves, and wellheads. The gas sample composition was then applied to the value components of WGX: Henry Hub natural gas, Waha basis differential, ethane, propane, n-butane, ibutane, and natural gasoline, adjusted for estimated transportation and fractionation $(\mathrm{T} \& \mathrm{~F})$ fees.

The tank vapor/VGX futures index was built using gas samples from Triple Crown's vapor recovery units ("VRUs") to quantify the value of gas leaking through thief hatches, enardos, and the VRUs themselves. The BTU content of tank vapor was observed to be approximately $2.5 \mathrm{x}$ that of the primary well stream, because of lower pressures and temperatures within storage tanks. The additional natural gas liquids ("NGL") content in the tank vapor sample elevates the conglomerate value of this gas to approximately $\$ 22.00 / \mathrm{MCF}$. The value components of VGX are the same as WGX, adjusted for the higher NGL content of the tank vapors.

Basic statistical techniques were utilized to generate the stationarity and seasonal variation in the constructed WGX, VGX, and DGX futures (Figure 2). Based on these results, $\$ 6.50 / \mathrm{MCF}, \$ 22.00 / \mathrm{MCF}$, and $\$ 2.50 / \mathrm{MCF}$ were chosen as conservative median value estimates for $1 \mathrm{MCF}$ of wet gas, tank vapor, and dry gas, respectively. Calculated gas prices were next reduced by gathering fees, net revenue interest, and severance tax. This allows the calculated payback period to represent a real cash-oncash exchange between campaign expenses and captured gas revenue. For this, Triple Crown applied $\$ 1 / \mathrm{MCF}$ of gathering fees, $75 \%$ net royalty interest, and $7.5 \%$ severance tax. This results in a realized wet gas price of $\$ 3.90 / \mathrm{MCF}$ and a realized dry gas price of $\$ 1.06 / \mathrm{MCF}$. For the purposes of the payback periods presented in this paper, all 
This is a non-peer reviewed preprint submitted to EarthArXiv.

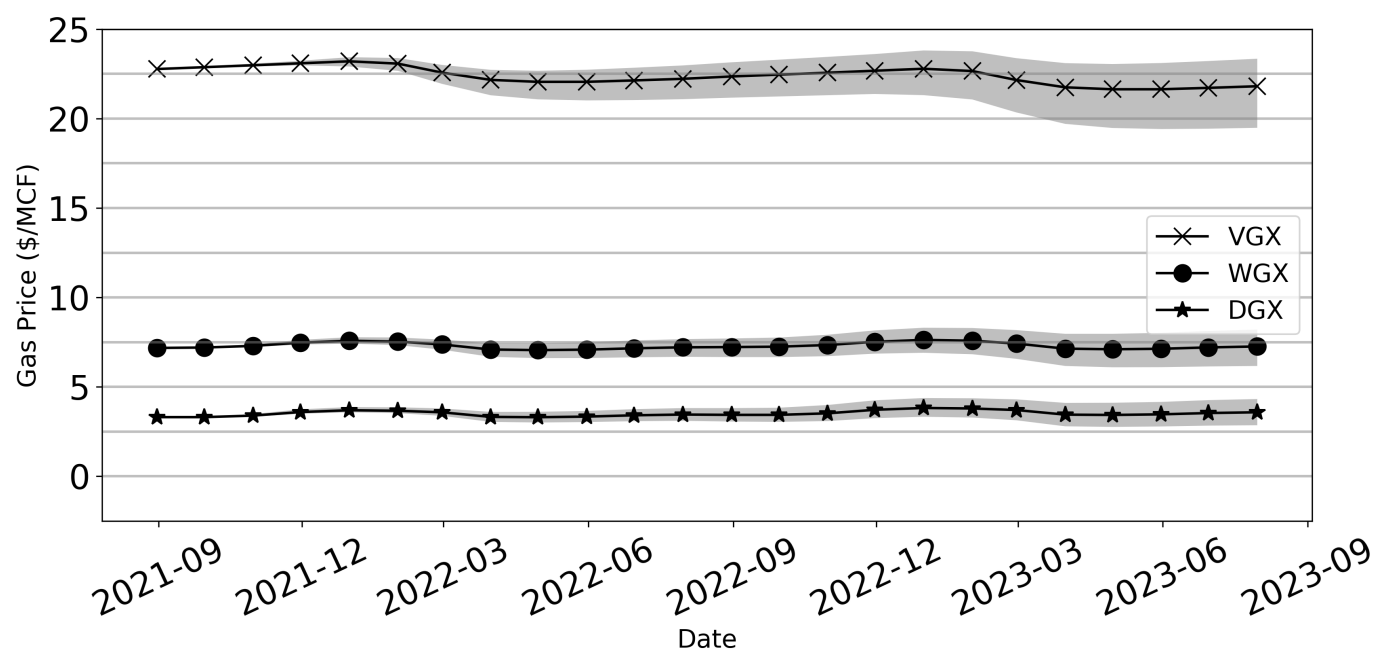

Figure 2. Statistical pricing models for tank vapor (VGX), wet gas (WGX), and dry gas (DGX) for gas samples taken across Triple Crown's gathering infrastructure, extrapolated for 3 years. Figure displays the median value for each constructed index, with the shaded area indicating the interquartile range based on daily EOD futures settlement data from CME since 2010.

gas was assumed to be either wet gas or dry gas. The VGX index pricing is included to demonstrate the significant benefit that could be gained from capturing tank vapors but is not used in any economic analyses.

\section{Case study and model results}

\subsection{Measured and modeled emissions}

The two surveys of Triple Crown's field confirmed a significant decrease in field emissions from the first to the second survey, with total emissions (including both revenue generating and non-revenue generating gas) decreasing 70\%. Gas emissions from sources that were captured and sold (and the focus of this study) declined $39 \%$. The remaining $31 \%$ of emissions from the first flyover were attributed to an unlit flare, which does not represent gas volumes that could have generated revenue. The $39 \%$ decline from the first to the second survey is similar to reductions observed by others following repeat airborne campaigns (e.g, Sridharan et al. (2020)).

The first survey detected losses of 1,288 MCF/Day from 9 sources that could be captured and sold. Repairs were generally simple and inexpensive (e.g., closing thief hatches, changing back pressure, and replacing worn seals), and were completed a few days following receipt of the survey report. Following the second survey 4 months later, 5 new sources that could be captured and sold were found to be emitting 783 $\mathrm{MCF} /$ Day. All sources required the same simple repairs as the first survey.

Overall, Triple Crown's asset-normalized emission rate improved from 6.4 to 3.9 MCF/Day/Surveyed Asset from the first to the second survey. The asset-normalized emission rates for Permian 25 Co., Permian 50 Co., and Permian 75 Co., representing a range of emissions for a similarly-sized operator, were calculated as $0.87,2.50$, and 5.91 MCF/Day/Surveyed Asset, respectively. Scaled to an operation of 200 assets produces full field emission rates of 175, 500, and $1182 \mathrm{MCF} /$ Day for Permian Co. 

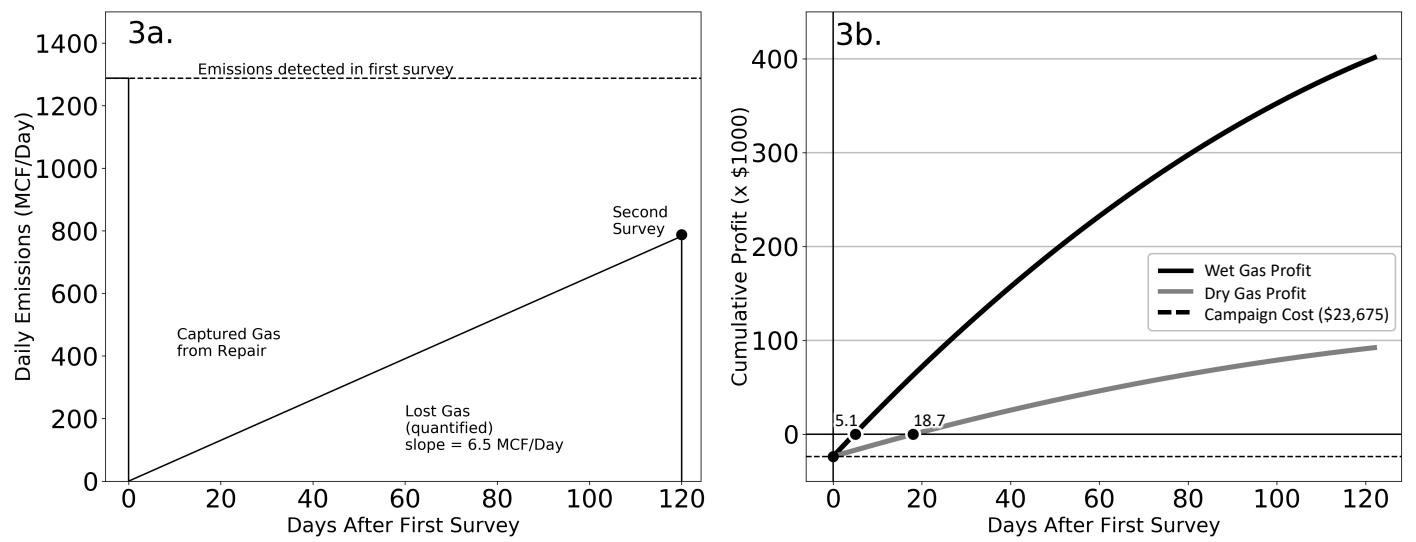

Figure 3. Monthly captured emissions and revenue. 3a.) Gas captured by Triple Crown; 3b.) Cumulative revenue resulting from gas captured following the first campaign, where on day 0 the cumulative revenue is negative by the cost of the survey and there are 0 emissions. Black dots indicate payback periods for each pricing model.

\subsection{Campaign expenses, captured gas revenue $G^{6}$ cash-on-cash payback periods}

Captured gas revenue resulting from the first and second campaign were calculated for Triple Crown. It was confirmed by an OGI camera that all 1,288 MCF/Day of leaks detected were successfully repaired, and Triple Crown's detectable emission rate was $0 \mathrm{MCF} /$ Day immediately following the campaign. A linear extrapolation of emissions was calculated, starting at $0 \mathrm{MCF} /$ Day, and ending at the $783 \mathrm{MCF} /$ Day emission rate found in the second survey four months later, resulting in an emission build rate of 6.5 MCF/Day (Figure 3a). This extrapolation was used to calculate the volume of gas capture leading up to the second survey, and therefore used to calculate the revenue generated by the first campaign. To determine a payback period, the $\$ 23,675$ campaign cost was modeled occurring on day 0 , with each following day accumulating the revenue generated by capturing the emissions (Figure $3 \mathrm{~b}$ ).

In the first month, captured wet gas revenue was $\$ 139,375$, resulting in a $\$ 115,700$ cash-on-cash profit to Triple Crown and a payback period of 5.1 days. The campaign continued to generate revenue with no extra repair costs, providing approximately $\$ 116,513, \$ 93,652$, and $\$ 70,790$ of profit in the next 3 months. This resulted in a cumulative cash-on-cash profit of $\$ 400,561$ over 4 months.

Assuming that the captured gas was only the methane quantified by Kairos's LeakSurveyor technology, dry gas revenue was $\$ 38,011$ in the first month, resulting in a $\$ 14,336$ cash-on-cash profit to Triple Crown and 18.7 day payout. The campaign continued to generate revenue with no extra repair costs, providing approximately $\$ 31,776, \$ 25,541$, and $\$ 19,306$ of profit in the next 3 months. This resulted in a cumulative cash-on-cash profit of $\$ 90,960$ over 4 months.

Analysis of Permian Co indicates that a short payback period would be an expected result for many small- to mid-sized Permian operations, even when accounting for higher campaign costs and/or lower field emissions (Table 3). Modeled Permian Co. revenue was similarly adjusted by estimated linear loss from new emissions postsurvey (modeled as daily increasing emissions over 6 months before reaching pre-survey levels). Payback periods ranged from 7.1 days to 51.9 days, increasing as captured emissions decreased. Permian 50 Co., representing a median emissions profile of a mid-sized 
This is a non-peer reviewed preprint submitted to EarthArXiv.

Table 3. Quantified captured emissions and associated revenue and payback period, for Triple Crown and Permian Co. Realized wet gas price is assumed at $\$ 3.90 / \mathrm{MCF}$.

\begin{tabular}{rcccc}
\hline & Triple Crown & Permian 25 Co. & Permian 50 Co. & Permian 75 Co. \\
\hline $\begin{array}{r}\text { Assets surveyed } \\
\text { Detected \& repaired }\end{array}$ & 201 & 200 & 200 & 200 \\
emissions (MCF/Day) & 1288 & 175 & 500 & 1182 \\
Total cost & $\$ 23,675$ & $\$ 30,000$ & $\$ 30,000$ & $\$ 30,000$ \\
$\begin{array}{r}\text { (survey + LDAR) } \\
\text { Total captured revenue, }\end{array}$ & $\$ 139,375$ & $\$ 18,782$ & $\$ 53,664$ & $\$ 126,862$ \\
first month post-survey & 5.1 & 51.9 & 16.8 & 7.1 \\
Payback (days) & & & &
\end{tabular}

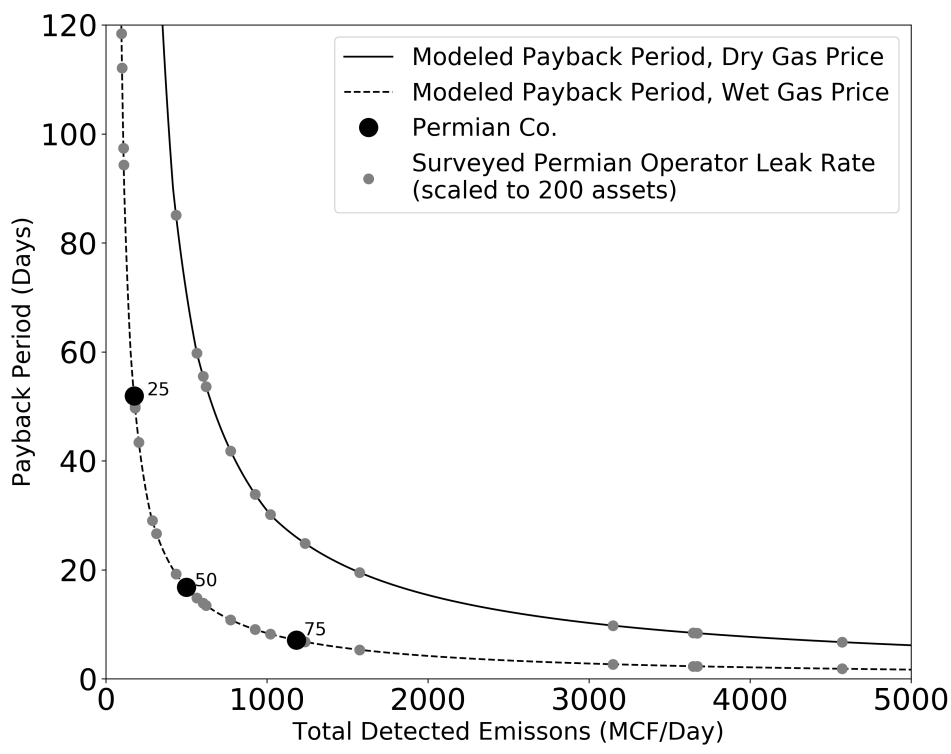

Figure 4. Modeled payback period for a theoretical operator with 200 assets across a range of detected field emissions, assuming a realized dry gas price of $\$ 1.06$ (solid line), and realized wet gas price of $\$ 3.90$ (dashed line). The three versions of Permian Co are shown along the wet gas curve, with constituent real-world operator payback as grey dots along both curves (with asset-normalized emission rates for each scaled to a 200 asset operation).

operator in the Permian, saw $\$ 53,664$ in captured gas revenue the first month with a payback period of 16.8 days.

A generalized model of the expected payback period for a Permian operator (with 200 assets), indicates that a payback period of 90 days or fewer could be accomplished for a campaign that fixed $114 \mathrm{MCF} /$ Day in emissions at a wet gas price of $\$ 3.90 / \mathrm{MCF}$, or $418 \mathrm{MCF} /$ Day at a dry gas price of $\$ 1.06 / \mathrm{MCF}$ (Figure 4). Across the 25 small- to mid-sized operators surveyed by Kairos, $56 \%$ had detected asset-normalized emission rates that would guarantee a payback period of fewer than 90 days at a dry gas price of $\$ 1.06 / \mathrm{MCF}$. At a wet gas price of $\$ 3.90 / \mathrm{MCF}$, this increased to $80 \%$ of operators. 
This is a non-peer reviewed preprint submitted to EarthArXiv.

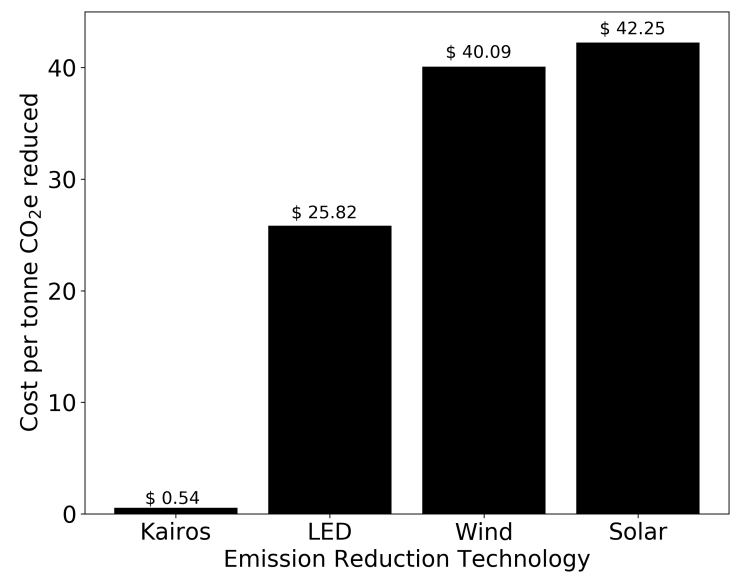

Figure 5. Cost effectiveness of four carbon reduction technologies, including Kairos surveys.

\subsection{Cost efficiencies of airborne methane survey relative to other green technologies}

The apparent cost efficiencies demonstrated by the short payback period for a given campaign are similarly impressive when compared to the cost efficiencies of other green technologies. According to Project Drawdown, solar photovoltaics, onshore wind, and LED lighting represent three mature, available, and effective solutions to reduce emissions globally (www.drawdown.org). We compare the cost per tonne of $\mathrm{CO}_{2} \mathrm{e}$ reduced for each of these technologies to that of Kairos, who reports a value for 2020 of 7.3 million tonnes of $\mathrm{CO}_{2}$ e reduced (www.kairosaerospace.com/2020-by-the-numbers). For simplicity, estimates for solar, wind, and LED technologies assume no operating or maintenance costs, no degradation in performance over time, and a US grid emissions offset of $418 \mathrm{~g} \mathrm{CO}_{2} / \mathrm{kWh}$.

The calculation makes the following considerations:

- Kairos: Estimate is based on voluntarily-reported emissions reductions achieved by Kairos customers, and includes all survey costs (flights, data processing, analysis, report generation, and report delivery), as well as assumed emission source repair costs.

- Solar: Assumes a $\$ 1$ million cost for a $1 \mathrm{MW}$ solar farm that will operate for 30 years.

- Wind: Assumes a $\$ 1.1$ million/MW capital cost for a wind farm that generates 2.19 million $\mathrm{kWh}$ per year for 30 years.

- LED: Costs are based on a LED bulb found on Amazon.com, with an assumed operation duration of 13 years.

Comparative analysis shows Kairos emissions survey technology to be a highly competitive option for cost effective carbon reduction, relative to wind, solar, and LED technology (Figure 5). Efficiencies are enhanced by the low cost of Kairos surveys as well as the large climate impact of methane, which is a significant component in natural gas. Overall, it costs $\$ 0.54$ to cut one tonne of $\mathrm{CO}_{2} \mathrm{e}$ using Kairos technology, compared to $\$ 25.82, \$ 40.09$, and $\$ 42.25$ for LED, wind, and solar, respectively.

These efficiencies scale favorably to the results of Triple Crown's first campaign, 
This is a non-peer reviewed preprint submitted to EarthArXiv.

which spent $\$ 0.11$ /tonne of $\mathrm{CO}_{2} \mathrm{e}$ (calculated by extrapolating the daily rate of captured emissions out to one year). Such cost savings are especially noteworthy given the range of carbon pricing (available and proposed) under various carbon markets. For example, the Energy Innovation and Carbon Dividend Act of 2021 (H.R. 2307) proposes an initial carbon price of $\$ 15$ per tonne of $\mathrm{CO}_{2} \mathrm{e}$ reduced. Under such a carbon pricing scheme, this campaign would represent a significant reduction in Triple Crown's carbon liability.

\section{Discussion and concluding remarks}

This study has demonstrated that a data-driven understanding of emissions is a powerful tool for increasing operator revenue through captured gas emissions. Source rate quantification provides a measure of both the total volume of gas that has been captured, as well as new losses that occur between surveys. This understanding is necessary to generate an adjusted estimate of revenue from captured gas that accounts for new losses that develop between LDAR surveys. As shown in the Triple Crown case study, emissions quantified in the second survey allowed for an accurate accounting of revenue and payback period resulting from the first campaign. This consideration makes a strong financial and environmental case for an emissions detection technology that can accurately quantify emission rate, such as that provided by Kairos, in contrast to other LDAR approaches.

Overall efficiencies of airborne surveys are key to turning gas emissions into profit. An airborne survey is a fast, inexpensive, and effective means to detect and repair gas emission sources. In Triple Crown's first survey, 1,288 MCF/Day in emissions were detected, investigated on the ground, repaired, and confirmed successful for $\$ 23,675$. At a wet gas price of $\$ 6.50 / \mathrm{MCF}$, netting out fees, royalty payments, and severance tax, this would result in a payback period of 5.1 days. Analysis of Permian Co. indicates that the efficiencies and revenue achieved in the Triple Crown case study are likely typical of a small to mid-sized operator in the Permian, with modeled payback periods of less than 90 days for $80 \%$ of operators, and less than 30 days for $64 \%$ of operators.

These efficiencies make campaigns of quarterly full-field surveys an affordable option for emissions control. While the appropriate inspection cadence will vary by operator, insight from regular inspections allows for baseline emissions to be quantified, and improvement demonstrated over time. Furthermore, the data can drive operational improvements, such as routine maintenance on flare pilots and enardo valves, that reduce or prevent new emissions (Sridharan et al., 2020). In the case of Triple Crown, an unlit flare detected in the first survey was determined to be due to an igniter in need of sanding. Based on this insight, Triple Crown inspected all flares and found two more nearing a similar condition. There were no unlit flares detected in the second survey.

Modern, survey-based LDAR using airborne detection has changed the calculus when it comes to the profitability of fixing emissions. Captured gas can be a significant source of added revenue, and full-field survey campaigns are an affordable method for accomplishing this. While the technology will no doubt continue to improve, the Triple Crown case study demonstrates the significant returns that are possible today using affordable state-of-the-art technology. 
This is a non-peer reviewed preprint submitted to EarthArXiv.

\section{Acknowledgements}

Special thanks to senior energy quant, AJT, for guidance on building indices for calculating WGX curves, and Viren Desai for the detailed statistical pricing models.

\section{References}

Alam, M.S., Paramati, S.R., Shahbaz, M., Bhattacharya, M., 2017. Natural gas, trade and sustainable growth: empirical evidence from the top gas consumers of the developing world. Applied Econ. 49, 635-649. https://doi.org/10.1080/00036846.2016.1203064

Berman, E.S.F., Wetherley, E.B., Jones, B.B., 2020. Tech. White Paper: Methane Detection. kairosaerospace.com/wp-content/uploads/2021/01/Kairos-Aerospace-MethaneDetection.pdf (accessed 6.1.21).

Brandt, A.R., Heath, G.A., Cooley, D., 2016. Methane Leaks from Natural Gas Systems Follow Extreme Distributions. Env. Sci. Tech. 50, 12512-12520. https://doi.org/10.1021/acs.est.6b04303

Duren, R.M., Thorpe, A.K., Foster, K.T., Rafiq, T., Hopkins, F.M., Yadav, V., Bue, B.D., Thompson, D.R., Conley, S., Colombi, N.K., Frankenberg, C., McCubbin, I.B., Eastwood, M.L., Falk, M., Herner, J.D., Croes, B.E., Green, R.O., Miller, C.E., 2019. California's methane super-emitters. Nature 575, 180-184. https://doi.org/10.1038/s41586-019-1720-3

Feijoo, F., Iyer, G.C., Avraam, C., Siddiqui, S.A., Clarke, L.E., Sankaranarayanan, S., Binsted, M.T., Patel, P.L., Prates, N.C., Torres-Alfaro, E., Wise, M.A., 2018. The future of natural gas infrastructure development in the United states. Applied Energy 228, 149-166. https://doi.org/10.1016/j.apenergy.2018.06.037

IEA, 2020. Gas 2020. IEA, Paris. https://www.iea.org/reports/gas-2020 (accessed 6.1.21).

Johnson, M.R., Tyner, D.R., Conley, S., Schwietzke, S., Zavala-Araiza, D., 2017. Comparisons of Airborne Measurements and Inventory Estimates of Methane Emissions in the Alberta Upstream Oil and Gas Sector. Env. Sci. Tech. https://doi.org/10.1021/acs.est.7b03525

Ravikumar, A.P., Wang, J., McGuire, M., Bell, C.S., Zimmerle, D., Brandt, A.R., 2018. "Good versus Good Enough?" Empirical Tests of Methane Leak Detection Sensitivity of a Commercial Infrared Camera. Env. Sci. Tech. 52, 2368-2374. https://doi.org/10.1021/acs.est.7b04945

Rutherford, J.S., Sherwin, E.D., Ravikumar, A.P., Heath, G.A., Englander, J., Cooley, D., Lyon, D., Omara, M., Langfitt, Q., Brandt, A.R., 2020. Closing the gap: Explaining persistent underestimation by US oil and natural gas production-segment methane inventories. Non-peer reviewed preprint.

Safari, A., Das, N., Langhelle, O., Roy, J., Assadi, M., 2019. Natural gas: A transition fuel for sustainable energy system transformation? Energy Sci. Eng. 7, 1075-1094. https://doi.org/10.1002/ese3.380

Sherwin, E.D., Chen, Y., Ravikumar, A.P., Brandt, A.R., 2021. Single-blind test of airplanebased hyperspectral methane detection via controlled releases. Elementa: Sci. of the Anthropocene 9. https://doi.org/10.1525/elementa.2021.00063

Sridharan, S., Lazarus, A., Reese, C., Wetherley, E., Bushko, K., Berman, E., 2020. Long Term, Periodic Aerial Surveys Cost Effectively Mitigate Methane Emissions, in: SPE Annual Technical Conference and Exhibition. Presented at the SPE Annual Technical Conference and Exhibition. https://doi.org/10.2118/201312-MS 